Running head: BUILDING MENTAL HEALTH RESPONSE CAPACITY

\title{
Manuscript title: A Systematic Approach to Building the Mental Health Response Capacity of Practitioners in a Postdisaster Context
}

\author{
Running title: BUILDING MENTAL HEALTH RESPONSE CAPACITY \\ Lennart Reifels, ${ }^{1}$ Bridget Bassilios, ${ }^{1}$ David Forbes, ${ }^{2}$ Mark Creamer, ${ }^{2}$ \\ Darryl Wade, ${ }^{2}$ Sally Coates, ${ }^{3}$ Malcolm Hopwood, ${ }^{4}$ Jane Pirkis ${ }^{1}$
}

\begin{abstract}
This paper presents the results of a summative evaluation of the training component of the Australian Government Mental Health Response to the 2009 bushfires in Victoria, Australia. With very little evidence available to date on comprehensive attempts at implementing multilevel training frameworks in the wake of natural disasters, the evaluation provides valuable insights into an effort that sought to build the capacity of practitioners to respond to the psychosocial and mental health consequences of a significant bushfire disaster at various levels of the response system. Key findings of the evaluation are discussed with regards to their relevance for the training of mental health practitioners in a broader range of disaster circumstances.
\end{abstract}

\section{Key words}

natural disaster; mental health; training; disaster relief planning; workforce; capacity

\section{Acknowledgements}

This work was supported through the Australian Government Department of Health and Ageing. The authors wish to thank the following agencies for their valuable input and insights, the Australian Government Department of Health and Ageing, the Victorian Department of Health, beyondblue: the national depression initiative, the Australian Psychological Society, 
Running head: BUILDING MENTAL HEALTH RESPONSE CAPACITY

the Australian Centre for Posttraumatic Mental Health, the Royal Australian and New Zealand College of Psychiatrists, General Practice Victoria, and Australian Healthcare Associates.

\section{Institutional Affiliations}

${ }^{1}$ Centre for Health Policy, Programs and Economics, Melbourne School of Population Health, University of Melbourne, Victoria, Australia.

${ }^{2}$ Australian Centre for Posttraumatic Mental Health, Department of Psychiatry, University of Melbourne, Victoria, Australia.

${ }^{3}$ beyondblue: the national depression initiative, Hawthorn West, Victoria, Australia.

${ }^{4}$ Royal Australian and New Zealand College of Psychiatrists, Melbourne, Victoria, Australia.

\section{Correspondence}

Lennart Reifels, Centre for Health Policy, Programs and Economics, Melbourne School of Population Health, University of Melbourne, Victoria 3010, Australia. Fax: +61 39348 1174, E-mail: 1.reifels@unimelb.edu.au

Key words: natural disaster, mental health, training, disaster relief planning, workforce, capacity 
Running head: BUILDING MENTAL HEALTH RESPONSE CAPACITY

In early 2009, Australia experienced one of its most extensive natural disasters during which bushfires devastated large parts of the state of Victoria. As a direct result of the fires, 173 people lost their lives, 51 townships were directly affected, and over 2,000 homes and many businesses and schools were destroyed (Commonwealth of Australia, 2009).

The international research literature demonstrates that disasters of this magnitude can significantly affect the mental health of impacted individuals and communities (Norris, Friedman, \& Watson, 2002; Ursano, Fullerton, Weisaeth, \& Raphael, 2007). Natural resilience and recovery processes play important roles in mediating the trajectory of individual disaster responses, and the impact of exposure to disasters such as bushfires on mental health can be mild, moderate or severe, short term or enduring and also variable over time (Laugharne, Van de Watt, \& Janca, 2011; Van Ommeren, 2006). The World Health Organization (WHO) estimates of the anticipated increase in mental health problems following disaster are summarised in Table 1 (Van Ommeren, 2006).

\section{Insert Table 1 here}

In view of the anticipated mental health impact of the bushfire disaster, the Australian Government contributed $\$ 7.5$ million towards the provision of mental health support to fireaffected individuals and communities. Under the Australian Government Mental Health Response to the Victorian Bushfires Measure (the Response), support was delivered through four components, namely: (1) primary mental health care services to support people most impacted by the bushfires; (2) training and support to professionals providing these services; (3) additional telephone-based counselling services to respond to broader levels of distress within the community; and (4) support for affected communities to reconnect and 
Running head: BUILDING MENTAL HEALTH RESPONSE CAPACITY

psychologically recover from the impact of the trauma over the long term. All Response components were integrated with the Victorian Government response to the fires.

\section{The Training Framework}

A scoping document devised by an expert reference group in the immediate fire aftermath outlined guiding parameters for the Response. These included a three-level framework which comprised three levels of intervention and care required in the community as well as corresponding training programs for providers. Table 2 outlines the full suite of training programs delivered through the Response aimed at building the mental health and psychosocial response capacity of providers at the three levels. Service delivery on the basis of this framework was operationalised through a resource-efficient stepped care model which progresses from the delivery of low-level support to more intensive treatments as the need arises.

Insert Table 2 here

Training development was carried out by agencies with expertise in the area of disaster response and trauma recovery and overseen by the Victorian Bushfire Cross-Professional Working Group. This group comprised representatives from both the Australian and Victorian Government health departments and key professional and mental health organisations, including the Australian Psychological Society (APS), the Australian Association of Social Workers, Occupational Therapy Australia, the Royal Australian College of General Practitioners, the Royal Australian and New Zealand College of Psychiatrists (RANZCP), the Austin Hospital and the Australian Centre for Posttraumatic Mental Health (ACPMH). 
Running head: BUILDING MENTAL HEALTH RESPONSE CAPACITY

\section{Nature and Scope of Training}

Level 1 training was based on a community capacity building approach which sought to equip generic community workers and leaders with a better understanding of the disaster recovery context and range of individual disaster responses, and the skills to facilitate self-care, low-level support and access to appropriate levels of care for affected community members (Wade et al., 2013). Jointly developed by ACPMH and beyondblue: the national depression initiative (and delivered by the latter), Level 1 training was largely consistent with a Psychological First Aid approach and designed for the support of common distress responses to disaster in the wider community.

Level 2 training sought to equip primary health care workers (such as counsellors, general practitioners and nurses) with a clear understanding of the Skills for Psychological Recovery (SPR) approach and the skills to deliver SPR in bushfire affected areas. As an evidence-informed skills-training model, SPR was based on six core skill sets which are known to facilitate recovery by way of assisting individuals to adopt helpful and adaptive strategies in relation to a range of trauma issues (Forbes et al., 2010). SPR was aimed at supporting individuals with mild to moderate levels of distress, specifically in those instances where Level 1 interventions alone would not suffice. Originally developed in response to Hurricane Katrina by the US National Center for PTSD (NCPTSD) and the National Child Traumatic Stress Network (NCTSN), SPR was adapted to an Australian context by ACPMH which also delivered the training in partnership with the APS.

Level 3 training encompassed two streams: 1) adult and 2) child and adolescent, which were delivered as separate and contextualised training programs to audiences of experienced psychiatrists and specialist mental health workers (e.g., psychologists). Training focused on 
Running head: BUILDING MENTAL HEALTH RESPONSE CAPACITY

latest evidenced-based interventions and therapeutic techniques for the treatment of individuals severely impacted by disaster and trauma. The Level 3 specialist stream was developed and delivered by ACPMH whereas the psychiatrist stream was adapted from these materials and delivered by RANZCP. Austin Hospital and Mater Health Services staff provided assistance for both streams.

In terms of the delivery format, Level 1 and 2 training adopted a Train the Trainer (TTT) approach involving the initial recruitment and up-skilling of a pool of trainers who then delivered training programs to respective target audiences. Level 3 training was entirely delivered by existing experts in the field. In addition to training services, the Response provided support to practitioners through resource materials, secondary consultation and enhancements to referral databases of professional organisations.

International disaster mental health responses prior to the Victorian bushfires more or less selectively employed training of providers in specific intervention approaches. Predominantly, these interventions included Psychological First Aid in relation to initial disaster distress (Allen et al., 2010; Brymer et al., 2006; Everly \& Flynn, 2006) and specific therapeutic techniques (such as cognitive behavioural or exposure therapy) for more severe clinical trauma presentations (CATS Consortium, 2010; Hamblen, Norris, Gibson, \& Lee, 2010; Marshall, Amsel, Neria, \& Suh, 2006). More recently, the Skills for Psychological Recovery approach has emerged as a strategy designed to fill the gap left by these former approaches by focusing on ongoing, mild to moderate mental health issues (Berkowitz et al., 2009; Forbes et al., 2010). 
Running head: BUILDING MENTAL HEALTH RESPONSE CAPACITY

The Response to the Victorian bushfire disaster was unique in that it was a systematic approach to training community members and health workers in evidence-informed interventions at all three levels of the framework. Insights and findings from the evaluation of this multilevel approach thus have significant potential for informing best practice in future disaster mental health training programs. 
Running head: BUILDING MENTAL HEALTH RESPONSE CAPACITY

\section{Method}

\section{Evaluation Design}

Table 3 outlines the design of the summative evaluation (Scriven, 1967, 1991) and the main data sources utilised to address key evaluation questions.

Insert Table 3 here

\section{Data Sources}

Existing evaluation reports. Five existing program-level evaluation reports were utilised as data sources in the overarching evaluation of the training Response and supplemented with follow-up log sheet data on Level 2 training.

Key informant interviews. Twelve representatives from seven agencies with direct involvement or insight into the training response (including the Victorian Health Department and training providers) participated in semi-structured interviews between August and October 2010. Interviewees were asked about their positive and negative experiences delivering training services, their perceptions of the benefits and challenges of training for mental health professionals, and how disaster training services could be further enhanced. Interviews were recorded and transcribed to enable analysis.

Training survey. An online training survey conducted in collaboration with Australian Healthcare Associates between August and September 2010 elicited practitioner responses in relation to various aspects of the training Response. Circulated through professional networks to general and mental health professionals, the survey yielded 81 responses from potential and actual training participants. 
Running head: BUILDING MENTAL HEALTH RESPONSE CAPACITY

\section{Data Analyses}

Existing evaluation reports were examined systematically with particular attention to data addressing evaluation questions. Training survey data and interview transcripts were analysed through a combination of basic descriptive analysis (frequencies, percentages) using MS Excel and thematic analysis using QSR NVIVO8. Step one of the thematic analysis involved coding responses on the basis of a pre-structured thematic coding system which was developed in direct alignment with key evaluation questions. In a second step, broad response categories were analysed for the existence of sub-themes that could further illuminate the data. 


\section{Results}

\section{Training Uptake and Participant Demographics}

Level 1 training (community workers and leaders). Forty-seven training workshops were delivered between August 2009 and November 2010. Of the 836 participants (64\% women, $36 \%$ men), the majority (74\%) were aged between 36-65 years. Participants included a mix of individual community members, businesses and specific community groups (including Council staff, Parks Victoria, community recovery committees). The TTT workshop was attended by nine facilitators who were trained and accredited by the end of August 2009.

Level 2 training (primary health care workers). Data were available on 23 of 24 workshops delivered between May and August 2009. Of the 290 participants, $79 \%$ were women and $21 \%$ men, with an average age of 48 years (range 22-78). Participants had been providing mental health services for an average of 14 years (range $0-41$ ) with professional backgrounds predominantly in psychology $(42 \%)$, social work (18\%), nursing (8\%), medicine (7\%) and counselling (5\%). On a four point scale ranging from 'none' to 'a lot', $42 \%$ percent of participants indicated a 'moderate' level of prior experience in treating people following trauma, whereas $39 \%$ indicated 'a little', 16\% 'a lot' and 4\% 'none'. The TTT workshop was attended by 32 participants who were trained by mid May 2009 .

Level 3 training (specialist mental health workers). Four adult and two child and adolescent stream workshops were delivered in September 2009 and followed up with the same number of booster sessions in November and December that year. Of the 114 workshop participants, 78 attended the adult and 36 the child and adolescent stream. Booster sessions attracted 39 (adult) and 17 (child and adolescent stream) participants. The audience comprised $83 \%$ women, $17 \%$ men (adult) and $77 \%$ women, $23 \%$ men (child and adolescent) with an 
Running head: BUILDING MENTAL HEALTH RESPONSE CAPACITY

average age of 49 years. On average, participants had been providing mental health services for more than 15 years, with professional backgrounds predominantly in psychology, social work, nursing, occupational therapy and psychiatry. Fifty-two percent of participants (adult) and $42 \%$ (child and adolescent) indicated a 'moderate' amount of prior experience in treating people following trauma, with another third in each stream indicating 'a little' and 14\% 'a lot'.

Level 3 training (psychiatrists). Three adult workshops and one child and adolescent workshop were delivered between December 2009 and March 2010. The combined attendance $(n=61)$ reflected $8 \%$ of all Victorian psychiatrists and $11 \%$ of child and adolescent psychiatrists. Participants were evenly split in gender terms, with a majority reporting ten or more years of practice experience. Participants were evenly distributed across either private or public practice or a combination of the two. Eighty percent of psychiatrists had a practice in a metropolitan or suburban location and $19 \%$ worked either partially or solely in rural areas.

\section{Key Training Benefits and Challenges for Practitioners}

Overall, the analysis of program evaluation data revealed a consistently high level of participant satisfaction with training at all three levels and the finding that learning outcomes were largely met (as indicated by such measures as participant ratings of enhanced knowledge, confidence and capability in relation to core content). The limited available follow-up data indicated that a proportion of practitioners had used skills learnt in training in their work with bushfire affected clients.

Level 1 training. Level 1 training was very favourably received by and beneficial to participants in terms of increasing their capacity to provide low-level support to people affected by the bushfires. Specifically, the evaluation demonstrated overall high participant satisfaction ratings (between 97-99\%) in relation to training format, content and materials as 
Running head: BUILDING MENTAL HEALTH RESPONSE CAPACITY

well as significant pre-post training increases in participant knowledge and confidence in relation to key aspects of responding to trauma (Wade et al., 2013).

Two participant follow-up telephone surveys $(n=70)$ conducted by the training provider in April and June 2010 confirmed positive pre- and post-workshop evaluations. Participant knowledge and confidence ratings were marginally higher for later workshops and only slightly decreased at follow-up. A majority of respondents $(86 \%)$ reported that they had utilised the training information.

Challenges encountered in training were minor and concerned the involvement of mental health lay audiences in support roles and the need for training to cater for diverse audience needs.

Level 2 training. As data on practitioner perceptions of Level 2 training have been published elsewhere (Forbes et al., 2010), a brief synopsis of relevant findings is provided here. Workshop evaluation data indicated that Level 2 training was positively received by and useful to practitioners as was evident in high overall ratings for items relating to: training format (68-96\% rated such aspects as 'good' or 'excellent'), high quality of the presentation (95-98\% 'agreed' or 'strongly agreed'), met learning objectives (91-96\% 'agreed' or 'strongly agreed') and usefulness of content (66-81\% rated individual modules 'quite' or 'very' useful). All six training modules were rated fairly evenly in terms of perceived usefulness with Module 1 (Gathering Information) rating only slightly lower than other modules.

Limited evidence on practitioner use of SPR in practice obtained from 61 follow-up log sheets (submitted by 20 practitioners in the three months following training) suggested that Module 1 (Gathering Information) was in fact the module used most commonly in practice (by 93\%) and that practitioners had greatest confidence in using. Other modules were utilised evenly in $67-77 \%$ of cases. Practitioners reported seeing clients for an average of four sessions 
Running head: BUILDING MENTAL HEALTH RESPONSE CAPACITY

with mean practitioner confidence levels rating highly for most modules (ranging from 4.3 out of 5 for Gathering Information to 3.8 for Managing Reactions). Practitioners further reported that clients had found SPR modules 'quite useful' (with overall scores ranging between 3.8 and 3.9). In $46 \%$ of cases SPR was used by practitioners directly in relation to bushfire issues and in $54 \%$ of cases in relation to ongoing problems in the wake of other traumatic events.

Challenges reported by SPR training participants related to a need for more interactive (versus didactic) presentation, insufficient challenge for experienced practitioners, a degree of variability in trainer skill and experience levels and the process for targeting and informing participants (with $32 \% \mathrm{n}=26$ of survey respondents indicating not having been offered Level 2 training).

Level 3 training (specialist mental health workers). Level 3 training was very positively received by participants and proved useful in their work with bushfire affected clients. Participant evaluations of adult and child and adolescent workshops yielded high ratings for items relating to: training format $(87-98 \%$ of adult and $67-97 \%$ of child and adolescent participants rated such aspects as 'good' or 'excellent'), high quality of the presentation (99-100\% of adult and 97\% child and adolescent participants 'agreed' or 'strongly agreed'), met learning objectives (97-100\% of adult and $89-100 \%$ child and adolescent participants 'agreed' or 'strongly agreed'), usefulness of content (88-98\% of adult and 91$100 \%$ child and adolescent participants rated individual modules as 'quite' or 'very' useful) and confidence to administer modules (73-97\% of adult and $80-100 \%$ child and adolescent participants were 'quite' or 'very' confident). Perceived usefulness and practitioner confidence rated evenly across modules, with confidence scores highest for psychoeducation and slightly lower for exposure and complicated grief modules. 
Running head: BUILDING MENTAL HEALTH RESPONSE CAPACITY

Follow-up workshops were rated equally positively in terms of format, presentation, and helpfulness of sessions. Participants of adult follow-up workshops reported having seen an average of 6.4 clients (range 0-35) who had presented with bushfire related issues. Client issues primarily related to anxiety (56\%), depression (31\%), grief and loss (31\%), PTSD (26\%), anger (13\%), family/relationship difficulties (13\%) and 'trauma' (8\%). Participants of child and adolescent follow-up workshops reported having seen an average of three children (range 014). Children primarily presented with issues relating to anger and PTSD. A majority of participants reported feeling confident in addressing presenting client issues (69\% child and adolescent, $79 \%$ adult) and that the initial training had aided their confidence in providing treatment (69\% child and adolescent, $87 \%$ adult).

Challenges encountered by specialist mental health workers in regards to Level 3 training related to the timing of training, the process for targeting and informing suitable participants (with $54 \% \mathrm{n}=44$ of survey respondents indicating not having been offered training), and a need for greater rehearsal space and ongoing support in relation to advanced intervention techniques.

Level 3 training (psychiatrists). Level 3 training for psychiatrists was overall very positively received and useful in increasing the interest, knowledge and competency levels of psychiatrists in responding to people traumatised by the bushfires. Participant workshop evaluations specifically indicated that training utilised materials of high quality ( $87 \%$ of participants rated quality 'high' or 'excellent') and accuracy ( $88 \%$ rated materials as 'highly' or 'extremely' accurate) that were also realistic ( $90 \%$ rated 'moderately' or greater).

Pre-post training comparisons indicated that workshops had contributed to significant increases in participants' level of interest in trauma (26\% increase in 'strong' or 'very strong' ratings), knowledge of clinical techniques (39\% increase in 'strong' or 'extensive' ratings) and 
Running head: BUILDING MENTAL HEALTH RESPONSE CAPACITY

competency in responding to bushfire related trauma ( $47 \%$ increase in 'moderate' or higher ratings).

Challenges encountered by psychiatrists in relation to Level 3 training were minimal and related to the lack of workshop availability outside of normal working hours and slightly greater discussion space required within the one day workshop format.

\section{Issues Associated with Implementation}

Delivery timelines. Since training delivery timelines reflect the availability of enhanced disaster mental health support services in the community, they are a key factor in determining the overall effectiveness of a disaster response. Figure 1 contrasts 'actual' training delivery timelines with 'envisaged' timeframes (from the Response scoping document) and expert advice on what may be considered 'optimum' timelines for training delivery in a postdisaster context.

\section{Insert Figure 1 here}

'Optimum' timelines which were derived by experts from ACPMH are applicable under ideal circumstances (i.e., where training programs and processes exist). The delivery of training, of course, is timed to coincide with readiness to deliver the intervention. The optimum timelines propose the best point for commencing that intervention, as well as the peak period of focus for that level. The end point of each intervention, however, should be interpreted loosely. There is no reason why any of those interventions should not continue as long as there is an identifiable need. Such an approach allows the psychosocial recovery program to focus not only on a past event, but also on building individual and community resilience for future stress and disaster. 
Running head: BUILDING MENTAL HEALTH RESPONSE CAPACITY

As Figure 1 indicates, almost all training programs experienced varying degrees of delay in delivery in contrast to comparative indicators. The only exception to this was the delivery of Level 2 training which largely coincided with envisaged timelines. However, in this context it is important to note that the devastating effects of major natural disasters on community resources and amenities pose significant practical challenges for the implementation of interventions. Key informant interview and training survey data highlighted several factors which had impacted on the implementation process.

Contextual challenges. Broader contextual challenges of service delivery in the fire aftermath included: i) destroyed infrastructure and practical issues with conducting training in fire ravaged areas; ii) multiple recovery efforts and competing demands for action; iii) a sense of information overload and diminished ability to take on new information on the part of community members; iv) practitioners being directly or indirectly affected by the fires; and v) divisions in communities between burnt 'black-belt' and unscathed 'green-belt' areas.

Barriers to provision. The lack of relevant training programs required that training materials had to be developed or customised and associated processes (i.e., funding contracts, reference groups and trainer training) established. The absence of a prior training needs analysis and data on existing practitioner skill-levels and gaps was identified as a significant barrier in the targeting of training.

Barriers evident in the promotion, recruitment and tailoring of programs included: i) short notice periods in training advertising; ii) practitioners lacking clarity on nature, intended audience and application of training; iii) limits of a 'shotgun' approach to targeting practitioners most likely to see fire affected clients; iv) difficulties engaging GPs and private providers (potentially attributable to a loss of income); v) existing workforce shortages (e.g., child and adolescent mental health); and vi) limited awareness of the varied work contexts of 
Running head: BUILDING MENTAL HEALTH RESPONSE CAPACITY

target audiences (including public, private, state and federally funded practitioners) reducing the ability to tailor sessions to practitioner needs.

Barriers to training transfer into practitioner practice included: i) time constraints in primary care settings; ii) limited capacity of consultant psychiatrists and long waiting lists; iii) known barriers to pathways of care in terms of client help seeking behaviour and referral pathways; iv) lack of clear articulation of the purpose and expectations around the use of training in practice; and v) limited availability of ongoing supervision and peer support.

Facilitating factors. Factors facilitating the provision of training services included: i) the pivotal role of the Victorian Bushfire Cross-Professional Training Working Group (and prior joint work of involved agencies in an Australian mental health network); ii) cooperation and coordination between federal and state governments which resulted in an integrated training response; and iii) the ability of training initiatives to build on lessons from previous natural disasters and link in with community recovery efforts. Further factors identified were: iv) provider engagement with community organisations which enhanced training uptake; v) provider awareness of local issues and disaster response context; vi) training provider / local host teleconferences; vii) provision of on-the-ground support; viii) use of language appropriate to lay audiences; ix) implementation flexibility which enhanced training responsiveness; and $\mathrm{x}$ ) the positive attitude, experience and initiative of participants. 


\section{Discussion}

Evaluation findings demonstrate that each of the training programs delivered as part of the Response had a beneficial effect in terms of increasing the self-reported knowledge, confidence and capability of relevant practitioners and community members to provide mental health support and interventions. Limited data showed that a proportion of participants successfully applied skills learnt in training in their interactions with bushfire affected community members. As a direct consequence of the training component of the Response, the overall capacity of the system to provide mental health support interventions under disaster circumstances has been significantly increased. Key evaluation findings and lessons from the implementation of a multilevel training framework in response to the Victorian bushfires yielded a number of suggestions which have implications for strengthening future disaster mental health training responses.

\section{Implications for Future Training Responses}

Regular training and capacity surveys. Evaluation findings highlight the importance of conducting prior training need and capacity surveys of relevant disaster mental health provider groups in order to effectively target and tailor future disaster response training. Such

surveys should ideally encompass an assessment of existing levels of provider skill, experience and capacity to participate in future disaster mental health responses. Professional organisations would be ideally placed to conduct these surveys at regular intervals in order to keep practitioner data bases up to date. This approach would simultaneously facilitate a better understanding of the scope and training needs of, as well as more ready access to, the disaster mental health workforce in emergency situations. 
Running head: BUILDING MENTAL HEALTH RESPONSE CAPACITY

Targeting and participant recruitment. Multilevel training frameworks following disaster can provide busy practitioners with multiple relevant training options. Therefore in order to optimise the targeting of training and avoid participant confusion, the importance of a well-coordinated approach to the promotion of the full suite of training services is paramount. Future training information needs to clearly articulate the nature, target audience, purpose, scope and application of training programs as well as any applicable prerequisites so that practitioners can make informed decisions about participation at the appropriate level(s). Beyond participant self-selection, there would be benefits in making relevant training obligatory for key personnel likely to be involved in disaster responses (U.S. Department of Health and Human Services, 1994). Additional strategies to attract private practitioners will need to be considered in order to broaden training coverage. A staged recruitment process, targeting practitioners from disaster affected and neighbouring areas and later those who have started seeing clients could help to ensure that training services optimally target relevant providers and translate into quality support for disaster affected individuals.

Program tailoring. Findings suggest that there is great merit in tailoring and contextualising the delivery of standard training programs to the work settings of target audiences and particulars of the local disaster context. While fidelity of the underpinning approach would remain paramount, contextualisation and tailoring proved to be key ingredients in the successful delivery of training programs under the Response, a finding which also resonates with the wider literature (Centre for Mental Health and NSW Institute of Psychiatry, 2000; U.S. Department of Health and Human Services, 1994; Weine et al., 2002). This further presupposes that trainers are sufficiently well-versed in approaches, familiar with local and professional contexts of participants and / or seek such information proactively.

Training delivery. Newly developed training programs should facilitate a more proactive approach to workforce capacity building and timely delivery of future disaster mental 


\section{Running head: BUILDING MENTAL HEALTH RESPONSE CAPACITY}

health response training. TTT approaches to capacity development benefit from a stronger focus on quality assurance and accreditation processes (throughout trainer selection, delivery and follow-up). A pool of qualified and accredited trainers with expertise in delivering trauma and disaster response training should be developed and maintained which could be supported through experts, a trainer network and ongoing professional development opportunities. The development of online and self-paced learning modules would be of particular merit at Levels 1 and 2, as it would increase the reach, accessibility and flexible delivery of training.

Sustained training effort. Disaster response training, whilst important, is not a substitute for ongoing practitioner skill development, particularly in relation to more advanced clinical intervention skills. Thus, developing the disaster response capacity of mental health professionals requires a preparatory and sustained training approach. Existing training followup mechanisms can be enhanced through models of expert supervision, peer support networks and clearer strategies for embedding practice change at an organisational and practitioner level. The explicit integration of training initiatives within disaster and emergency response plans warrants further consideration in this context (Centre for Mental Health and NSW Institute of Psychiatry, 2000).

\section{Strengths and Limitations of the Evaluation}

In addition to a reliance on participant self-reports the evaluation was limited by a lack of data on: i) the nature, scope and training needs of the disaster mental health workforce; ii) the ongoing use of training in practice; and iii) consumer outcomes. Thus, caution needs to be exercised in interpreting study findings specifically in relation to training uptake and resulting impact at consumer level. Despite these limitations, the evaluation provided valuable lessons for future training responses. 
Running head: BUILDING MENTAL HEALTH RESPONSE CAPACITY

\section{Conclusion}

The available evidence suggests that multilevel training frameworks can be usefully implemented in a post-disaster context in order to strengthen the mental health response capacity of practitioners and community members at various levels of the response system. Key learnings from the implementation process highlight the importance of consistency and clarity in the targeting and promotion of training programs, the need for comprehensive data collection, and the benefits of a sustained approach to building practitioner capacity, all of which can contribute to enhancing future training efforts in the wake of natural disasters. 


\section{References}

Allen, B., Brymer, M. J., Steinberg, A. M., Vernberg, E. M., Jacobs, A., Speier, A. H., \& Pynoos, R. S. (2010). Perceptions of Psychological First Aid among providers responding to hurricanes Gustav and Ike. Journal of Traumatic Stress, 23(4), 509-513.

Berkowitz, S., Bryant, R. A., Brymer, M. J., Hamblen, J., Jacobs, A., Layne, C., . . Watson, P. (2009). Skills for Psychological Recovery: Field Operations Guide: Unpublished draft edition: National Centre for PTSD and National Child Traumatic Stress Network.

Brymer, M. J., Jacobs, A., Lane, C. M., Pynoos, R. S., Ruzek, J. I., Steinberg, A. M., . . Watson, P. (2006). Psychological First Aid: Field operations guide, 2nd Edition. July 2006: National Child Traumatic Stress Network and National Centre for PTSD. Available on: www.nctsn.org and www.ncptsd.va.gov.

CATS Consortium. (2010). Implementation of CBT for youth affected by the World Trade Center disaster: Matching need to treatment intensity and reducing trauma symptoms. Journal of Traumatic Stress, 23(6), 699-707. doi: 10.1002/jts.20594

Centre for Mental Health and NSW Institute of Psychiatry. (2000). Disaster mental health response handbook: An educational resource for mental health professionals involved in disaster management. North Sydney, New South Wales, Australia: New South Wales Health.

Commonwealth of Australia. (2009). Victorian bushfires - January'February 2009 Retrieved 25/10/10, 2010, from http://www.disasterassist.gov.au/CurrentDisasters/Pages/vic_fires_09.aspx

Everly, G. S., \& Flynn, B. W. (2006). Principles and practical procedures for acute psychological first aid training for personnel without mental health experience. International Journal of Emergency Mental Health, 8(2), 93-100.

Forbes, D., Fletcher, S., Wolfgang, B., Varker, T., Creamer, M., Brymer, M. J., . . Bryant, R. A. (2010). Practitioner perceptions of Skills for Psychological Recovery: A training program for health practitioners in the aftermath of the Victorian bushfires. Australian and New Zealand Journal of Psychiatry, 44(12), 1105-1111.

Hamblen, J. L., Norris, F. H., Gibson, L., \& Lee, L. (2010). Training community therapists to deliver cognitive behavioral therapy in the aftermath of disaster. International Journal of Emergency Mental Health, 12(1), 33-40.

Laugharne, J., Van de Watt, G., \& Janca, A. (2011). After the fire: The mental health consequences of fire disasters. Current Opinion in Psychiatry, 24(1), 72-77.

Marshall, R. D., Amsel, L., Neria, Y., \& Suh, E. J. (2006). Strategies for dissemination of evidence-based treatments: Training clinicians after large-scale disasters. In F. H. Norris, S. Galea, M. J. Friedman \& P. J. Watson (Eds.), Methods for disaster mental health research (pp. 226-239). New York: Guilford Press. 
Norris, F. H., Friedman, M. J., \& Watson, P. (2002). 60,000 disaster victims speak: Part II. Summary and implications of the disaster mental health research. Psychiatry, 65(3), 240-260.

Scriven, M. (1967). The methodology of evaluation. In M. E. Gredler (Ed.), Program Evaluation (2006 ed.). New Jersey: Prentice Hall.

Scriven, M. (1991). Beyond formative and summative evaluation. In M. E. Gredler (Ed.), Program Evaluation (1996 ed.). New Jersey: Prentice Hall.

U.S. Department of Health and Human Services. (1994). Disaster response and recovery: A handbook for mental health professionals. DHHS Pub. No. (SMA) 94-3010.

Washington, D.C.: Center for Mental Health Services, Substance Abuse and Mental Health Services Administration.

Ursano, R. J., Fullerton, C. S., Weisaeth, L., \& Raphael, B. (2007). Individual and community responses to disasters. In R. J. Ursano, C. S. Fullerton, L. Weisaeth \& B. Raphael (Eds.), Textbook of disaster psychiatry (pp. 3-26). Cambridge: University Press.

Van Ommeren, M. (2006). Inter-Agency Standing Committee (IASC) Guidance on mental health and psychosocial support in emergency settings. Paper presented at the Public Health Pre-Deployment Training, Chavannes de Bogis, Switzerland.

Wade, D., Varker, T., Coates, S., Fitzpatrick, T., Shann, C., \& Creamer, M. (2013). A mental health training program for community members following a natural disaster. Disaster Health, 1(1), 1-4.

Weine, S., Danieli, Y., Silove, D., Van Ommeren, M., Fairbank, J. A., \& Saul, J. (2002). Guidelines for international training in mental health and psychosocial interventions for trauma exposed populations in clinical and community settings. Psychiatry, 65(2), 156164. 
Running head: BUILDING MENTAL HEALTH RESPONSE CAPACITY

Figure 1: Actual, envisaged and optimum timelines for delivery of training programs

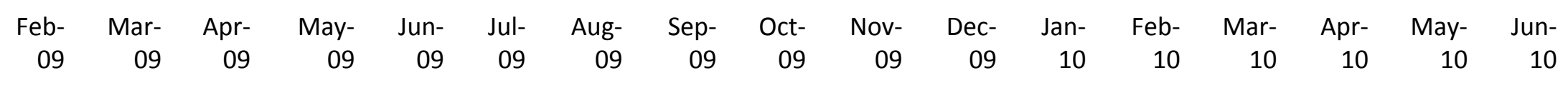

\section{Level 1 \\ Actual \\ Envisaged \\ Optimum \\ Level 2 \\ Actual \\ Envisaged \\ Optimum}

\section{Level 3}

Actual

Envisaged

Optimum

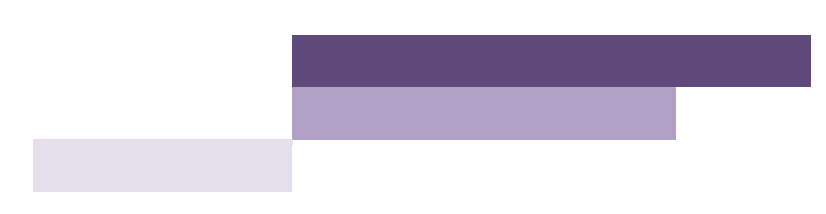

Level 3

Actual

Envisaged

Optimum

NB. 'Actual' - actual delivery timelines; 'Envisaged' - delivery timelines outlined in the mental health response scoping document; 'Optimum' expert best practice advice on optimal delivery timeframes 
Running head: BUILDING MENTAL HEALTH RESPONSE CAPACITY

Table 1: Summary of WHO prediction of the prevalence of psychosocial problems after an emergency

\begin{tabular}{|c|c|c|}
\hline & $\begin{array}{r}\text { Before } \\
\text { emergency - } \\
\text { 12-month } \\
\text { prevalence }\end{array}$ & $\begin{array}{r}\text { After emergency - } \\
\text { 12-month } \\
\text { prevalence }\end{array}$ \\
\hline $\begin{array}{l}\text { Severe mental disorder (such as psychosis, severe } \\
\text { depression, severe disabling anxiety disorder) }\end{array}$ & $2-3 \%$ & $3-4 \%$ \\
\hline $\begin{array}{l}\text { Mild or moderate mental disorder (such as mild and } \\
\text { moderate depression or anxiety) }\end{array}$ & $10 \%$ & $\begin{array}{l}20 \% \text { (reduces to } \\
15 \% \text { with natural } \\
\text { recovery) }\end{array}$ \\
\hline $\begin{array}{l}\text { Moderate or severe psychological/social distress (no } \\
\text { formal disorder but severe distress) }\end{array}$ & No estimate & $\begin{array}{l}\text { Large percentage } \\
\text { (reduces due to } \\
\text { natural recovery) }\end{array}$ \\
\hline Mild psychological/social distress & No estimate & $\begin{array}{l}\text { Small percentage } \\
\text { (increases over time) }\end{array}$ \\
\hline
\end{tabular}

Adapted from Van Ommeren (2006) 
Running head: BUILDING MENTAL HEALTH RESPONSE CAPACITY

Table 2: Nature and scope of training services provided as part of the Response

\begin{tabular}{|c|c|c|c|c|}
\hline $\begin{array}{l}\text { Training / } \\
\text { Level }\end{array}$ & $\begin{array}{l}\text { Target } \\
\text { audience }\end{array}$ & Delivery format & Training content & Training aims / Intervention scope \\
\hline $\begin{array}{l}\text { Level } 1 \\
\text { Community } \\
\text { Support \& } \\
\text { Training } \\
\text { Program }\end{array}$ & $\begin{array}{l}\text { Generic } \\
\text { community } \\
\text { workers and } \\
\text { leaders }\end{array}$ & $\begin{array}{l}\text { Train the Trainer model } \\
\text { ( } 2 \text { day workshop) } \\
\text { Participant training } \\
\text { ( } 3 \text { h workshop, also } \\
\text { available as } 1.5 \text { or } 2 \text { h) } \\
\text { Single facilitator } \\
\text { Targeted follow up } \\
\text { information provided at } \\
\text { 4-6 weeks } \\
\text { 8-10 weeks } \\
12-14 \text { weeks }\end{array}$ & $\begin{array}{l}\text { Learning objectives: } \\
\text { 1. Knowledge of bushfire psychosocial } \\
\text { recovery framework } \\
\text { 2. Understanding impacts on community } \\
\text { and individuals and the range of } \\
\text { responses } \\
\text { 3. Understanding of common mental } \\
\text { health and wellbeing issues and } \\
\text { treatment approaches } \\
\text { 4. Recognising early signs of distress } \\
\text { symptoms } \\
\text { 5. Strategies for self care and for } \\
\text { supporting families and friends } \\
\text { 6. When and how to refer to professional } \\
\text { supports } \\
\text { Knowledge of services and supports } \\
\text { available }\end{array}$ & $\begin{array}{l}\text { To assist key members of the community to: } \\
\text { 1. Recognise when others, such as family, } \\
\text { friends, colleagues, customers or } \\
\text { clients, are having trouble coping } \\
\text { 2. Provide advice on simple strategies that } \\
\text { will promote normal recovery and help } \\
\text { people access the support they need } \\
\text { from within their own community } \\
\text { 3. Enable participants to provide useful } \\
\text { advice on how and when to seek } \\
\text { professional help } \\
\text { 4. Assist participants in looking after their } \\
\text { own psychological well-being and } \\
\text { setting appropriate limits to their } \\
\text { support for others. } \\
\text { Level of Care 1: Designed for population level } \\
\text { support of common distress responses usually in } \\
\text { the immediate aftermath of trauma }\end{array}$ \\
\hline $\begin{array}{l}\text { Level } 2 \\
\text { Skills for } \\
\text { Psychological } \\
\text { Recovery (SPR) }\end{array}$ & $\begin{array}{l}\text { Primary } \\
\text { health care } \\
\text { workers }\end{array}$ & $\begin{array}{l}\text { Train the Trainer model } \\
\text { (2 day workshop) } \\
\text { Participant training } \\
\text { (1 day workshop) } \\
\text { Co-facilitated }\end{array}$ & $\begin{array}{l}\text { Six modules: } \\
\text { 1. Gathering information and prioritising } \\
\text { 2. Bsistance } \\
\text { 3. Promoting positive activities } \\
\text { 4. Managing reactions } \\
\text { 5. Promoting helpful thinking } \\
\text { 6. Rebuilding healthy social connections }\end{array}$ & $\begin{array}{l}\text { Training aims to provide participants with: } \\
\text { 1. A clear understanding and knowledge } \\
\text { of the rationale for the use of SPR } \\
\text { 2. The skills to deliver SPR as an } \\
\text { intervention in the bushfire affected } \\
\text { areas } \\
\text { Level of Care 2: Designed for individuals with } \\
\text { mild to moderate sub-clinical levels of distress }\end{array}$ \\
\hline
\end{tabular}


Running head: BUILDING MENTAL HEALTH RESPONSE CAPACITY

\begin{tabular}{|c|c|c|c|c|}
\hline $\begin{array}{l}\text { Level } 3 \\
\text { Psychological } \\
\text { Treatment of } \\
\text { Common } \\
\text { Mental Health } \\
\text { Problems after } \\
\text { Trauma and } \\
\text { Disaster }\end{array}$ & $\begin{array}{l}\text { Specialist } \\
\text { mental health } \\
\text { workers }\end{array}$ & $\begin{array}{l}\text { Participant training adult } \\
\text { ( } 2 \text { day workshop }+1 \text { day } \\
\text { booster workshop at three } \\
\text { months) Co-facilitated } \\
\text { Participant training child } \\
\text { and adolescent } \\
\text { ( } 2 \text { day workshop }+1 \text { day } \\
\text { booster workshop at three } \\
\text { months) Co-facilitated }\end{array}$ & $\begin{array}{l}\text { Seven adult and eight child and adolescent } \\
\text { modules: } \\
\text { 1. Psychoeducation } \\
\text { 2. Arousal (anxiety and anger) } \\
\text { management and distress } \\
\text { 3. Behavioural activation } \\
\text { 4. Exposure (in vivo and imaginal) } \\
\text { 5. Cognitive therapy } \\
\text { 6. Complicated grief } \\
\text { 7. Relapse prevention } \\
\text { 8. Parents \& Parenting (Child \& } \\
\text { Adolescent only) }\end{array}$ & $\begin{array}{l}\text { The training aims to inform and educate } \\
\text { specialist mental health professionals in } \\
\text { evidence based treatment interventions for } \\
\text { common mental health problems which occur } \\
\text { (or are worsened) in adults and children / } \\
\text { adolescents following trauma and disaster. } \\
\text { Level of Care 3: Designed for a minority of } \\
\text { survivors who experience significant mental } \\
\text { health conditions }\end{array}$ \\
\hline $\begin{array}{l}\text { Level } 3 \\
\text { Victorian } \\
\text { Bushfire } \\
\text { Response } \\
\text { Project }\end{array}$ & Psychiatrists & $\begin{array}{l}\text { Participant training adult } \\
\text { (1 day workshop) } \\
\text { Co-facilitated } \\
\text { Participant training child } \\
\text { and adolescent } \\
\text { (1 day workshop) } \\
\text { Single facilitator }\end{array}$ & $\begin{array}{l}\text { Topics covered } \\
\text { 1. Bushfire context } \\
\text { 2. Latest research into psychiatric } \\
\text { consequences of severe trauma } \\
\text { 3. Evidence based treatment guidelines } \\
\text { 4. Latest research in treatment modalities } \\
\text { a. Exposure treatments } \\
\text { b. Cognitive therapy } \\
\text { c. Goal setting and activity } \\
\text { d. Managing anger } \\
\text { e. Treatment of complicated grief } \\
\text { f. Relapse prevention } \\
\text { g. Managing comorbidity } \\
\text { h. Pharmacotherapy } \\
\text { i. Inpatient treatment } \\
\text { Referral pathways for severe mental } \\
\text { illness } \\
\text { 6. Availability of community supports } \\
\text { 7. Shared care processes with GPs and } \\
\text { Allied Mental Health Professionals } \\
\text { through Medicare } \\
\text { 8. Current controversies in the } \\
\text { management of severe trauma } \\
\text { responses }\end{array}$ & $\begin{array}{l}\text { The training aim is to up-skill psychiatrists in } \\
\text { order to support them in their dealing with } \\
\text { people traumatised by the Victorian bushfires } \\
\text { Level of Care 3: Designed for a minority of } \\
\text { survivors who experience significant mental } \\
\text { health conditions }\end{array}$ \\
\hline
\end{tabular}


Table 3: Data sources in relation to evaluation questions

\begin{tabular}{|c|c|c|c|}
\hline & \multicolumn{3}{|c|}{ Data Sources } \\
\hline Evaluation Questions & 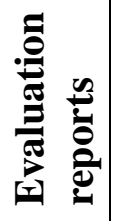 & 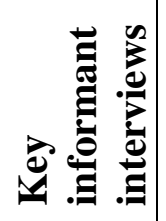 & 党 \\
\hline $\begin{array}{l}\text { 1. What is the level of uptake of support and } \\
\text { training by mental health professionals? }\end{array}$ & $\sqrt{ }$ & $\sqrt{ }$ & $\sqrt{ }$ \\
\hline $\begin{array}{l}\text { 2. What is the profile (socio-demographic) of } \\
\text { health professionals accessing support and } \\
\text { training? }\end{array}$ & $\sqrt{ }$ & & $\sqrt{ }$ \\
\hline $\begin{array}{l}\text { 3. What are the benefits and challenges of the } \\
\text { support and training services for mental health } \\
\text { professionals? }\end{array}$ & $\sqrt{ }$ & $\sqrt{ }$ & \\
\hline $\begin{array}{l}\text { 4. What issues are associated with providing } \\
\text { training and support for mental health } \\
\text { professionals offering bushfire services? }\end{array}$ & $\sqrt{ }$ & $\sqrt{ }$ & \\
\hline
\end{tabular}




\section{University Library}

\section{- M M N E R VA A gateway to Melbourne's research publications}

Minerva Access is the Institutional Repository of The University of Melbourne

\section{Author/s:}

Reifels, L;Bassilios, B;Forbes, D;Creamer, M;Wade, D;Coates, S;Hopwood, M;Pirkis, J

Title:

A systematic approach to building the mental health response capacity of practitioners in a post-disaster context

\section{Date:}

2013-01-01

\section{Citation:}

Reifels, L., Bassilios, B., Forbes, D., Creamer, M., Wade, D., Coates, S., Hopwood, M. \& Pirkis, J. (2013). A systematic approach to building the mental health response capacity of practitioners in a post-disaster context. ADVANCES IN MENTAL HEALTH, 11 (3), pp.246-256. https://doi.org/10.5172/jamh.2013.11.3.246.

Persistent Link:

http://hdl.handle.net/11343/58340 